(c) American Dairy Science Association, 2006.

\title{
Development and Evaluation of Models to Predict the Feed Intake of Dairy Cows in Early Lactation
}

\author{
M. A. Shah ${ }^{1,2}$ and M. R. Murphy \\ Department of Animal Sciences, University of Illinois, Urbana 61801
}

\begin{abstract}
Inaccurate prediction of dry matter intake (DMI) limits the ability of current models to anticipate the technical and economic consequences of adopting different strategies for production management on individual dairy farms. The objective of the present study was to develop an accurate, robust, and broadly applicable prediction model and to compare it with the current NRC model for dairy cows in early lactation. Among various functions, an exponential model was selected for its best fit to DMI data of dairy cows in early lactation. Daily DMI data $(\mathrm{n}=8,547)$ for 3 groups of Holstein cows (at Illinois, New Hampshire, and Pennsylvania) were used in this study. Cows at Illinois and New Hampshire were fed totally mixed diets for the first 70 $\mathrm{d}$ of lactation. At Pennsylvania, data were for the first $63 \mathrm{~d}$ postpartum. Data from Illinois cows were used as the developmental dataset, and the other 2 datasets were used for model evaluation and validation. Data for BW, milk yield, and milk composition were only available for Illinois and New Hampshire cows; therefore, only these 2 datasets were used for model comparisons. The exponential model, fitted to the individual cow daily DMI data, explained an average of $74 \%$ of the total variation in daily DMI for Illinois data, $49 \%$ of the variation for New Hampshire data, 67\% of the variation for Pennsylvania data, and $64 \%$ of the variation overall. Based on all model selection criteria used in this study, the exponential model for prediction of weekly DMI of individual cows was superior to the current NRC equation. The exponential model explained $85 \%$ of the variation in weekly mean DMI compared with $42 \%$ for the NRC equation. Compared with the relative prediction error of $6 \%$ for the exponential model, that associated with prediction using the NRC equation was $14 \%$. The overall mean square prediction error value for individual cows was 5 -fold higher for the NRC equation than for the exponential model (10.4
\end{abstract}

\footnotetext{
Received November 23, 2004.

Accepted September 19, 2005

${ }^{1}$ Present address: Lethbridge Research Centre, Agriculture and Agri-Food Canada, Lethbridge, AB, Canada T1J 4B1.

${ }^{2}$ Corresponding author: shahm@agr.gc.ca
}

vs. $2.0 \mathrm{~kg}^{2} / \mathrm{d}^{2}$ ). The consistently accurate and robust prediction of DMI by the exponential model for all datasets suggested that it could safely be used for predicting DMI in many circumstances.

Key words: dry matter intake, model, early lactation, dairy

\section{INTRODUCTION}

An accurate method of predicting and maximizing the feed consumption of dairy cows in early lactation is important to provide balanced diets, to optimize production (Murphy and Shah, 1999), and to formulate cost-effective rations (Roseler et al., 1993). Prediction of feed intake by dairy cattle has received much attention for many decades (Ingvartsen, 1994), and numerous models of it have been developed. The traditional motivation for this interest is that providing a balanced diet increases production, efficiency, and profitability (Ingvartsen and Andersen, 2000).

Critical evaluation of some of the models currently in use indicates that they are inaccurate or not universal because they exclude important factors known to influence DMI or were developed to apply to a certain type of cow and diet (Mertens, 1995; Ingvartsen and Andersen, 2000). A major limitation of these models is their inability to account for large day-to-day variation in feed intake. In particular, nearly all models are incapable of accurately predicting DMI in early lactation (Ingvartsen, 1994; Mertens, 1995). It is well known that feed intake is variable and increases after calving, reaching a peak between 70 and 98 DIM (Murphy and Shah, 1999). During early lactation, the increase in milk production leads the increase in DMI, and there is an abrupt reduction in BW of cows after calving as body reserves are rapidly mobilized to supply required nutrients. Although recently published models (NRC, 2001; Fuentes-Pila et al., 2003) included week or month of the lactation as a factor to account for the rapid rate of change in DMI during early lactation, use of weekly or monthly mean values for DMI again ignores day-today variation in DMI. Variation in feed intake, per se, has received relatively little attention (Murphy and Shah, 1999; Forbes and Provenza, 2000). Ingvartsen et al. (1992) reported that day-to-day variation in feed 
intake accounted for $66.5 \%$ of the total variation in the DMI of growing dairy cattle; therefore, weekly mean data cannot substitute for daily DMI data, as previously proposed by Roseler et al. (1997a).

The NRC (2001) model did not include dietary factors because "equations containing dietary factors are best used to evaluate post-consumption rather than to predict what will be consumed." The NRC (2001) model included $4 \% \mathrm{FCM}$ and $\mathrm{BW}^{0.75}$ as variables for prediction of DMI. Although milk yield is positively correlated with DMI, 4\% FCM is an output variable that is not known at the time of DMI prediction (Ingvartsen, 1994) and should not be included in DMI prediction models. The argument for not including dietary factors in DMI prediction models (NRC, 2001) can also be applied to milk yield. Holter et al. (1996), Roseler et al. (1997b), and Ingvartsen and Andersen (2000) noted that the efficiency of $4 \% \mathrm{FCM}$ production differed between bSTtreated and control cows; therefore, $4 \% \mathrm{FCM}$ is not an accurate or appropriate predictor of DMI, even though it is closely correlated with DMI.

Animal weight is considered important in most models predicting DMI, including the NRC (2001) model. During early lactation tissue mobilization occurs at the same time that feed intake is rapidly, if belatedly, increasing. Chilliard et al. (1991) suggested that there was a 4-kg increase in gut fill for each kilogram increase in DMI. Decreases in empty BW are masked by increases in gut fill such that changes in BW during early lactation do not accurately reflect changes in empty BW. Thus, inclusion of these factors and multiple regression approaches reduce the accuracy (Mertens, 1995; Ingvartsen and Andersen, 2000), and robustness (Fuentes-Pila et al., 1996) of these models.

Inaccurate prediction of DMI limits the ability of current models to anticipate the technical and economic consequences of adopting different strategies for production management on individual dairy farms (Fuentes-Pila et al., 1996). Additionally, all of the functions in current models include polynomial or logarithmic terms that are difficult to interpret biologically; therefore, a more accurate, robust, and universal model needs to be developed to predict the daily DMI of dairy cows in early lactation. The robustness and accuracy of the NRC (2001) model also needs to be evaluated for conditions different from those under which it was developed. Therefore, the objective of present study was to develop a prediction model that could appropriately address these concerns and be compared with the NRC (2001) model for estimating the daily feed intake of dairy cows in early lactation.

\section{MATERIALS AND METHODS}

\section{Datasets}

Data contained daily DMI observations $(\mathrm{n}=8,547)$ from 3 different and independent experiments at 3 dif-
Table 1. Least squares means (SEM) of data used in model development, evaluation, and validation

\begin{tabular}{lccc}
\hline & & New & \\
Measure & Illinois $^{1}$ & Hampshire $^{2}$ & Pennsylvania $^{3}$ \\
\hline DMI, kg/d & $20.6(0.2)$ & $23.9(0.2)$ & $20.8(0.6)$ \\
Milk yield, kg/d & $39.6(0.3)$ & $47.6(0.4)$ & $44.1(1.1)$ \\
$3.5 \%$ FCM, kg/d & $35.9(0.4)$ & $51.2(0.5)$ & $44.1(1.6)$ \\
BW, kg & $637(3.0)$ & $661(5.0)$ & $654(15.0)$ \\
Cows, no. & 35 & 34 & 59 \\
\hline
\end{tabular}

${ }^{1}$ Erickson et al. (2000).

${ }^{2}$ Wasserstorm (1996).

${ }^{3}$ Dann et al. (1999).

ferent locations (Table 1). Two datasets, Illinois and New Hampshire, involved cows from parturition to wk 10 postpartum. A third set, Pennsylvania, involved cows in their first 9 wk postpartum.

Illinois data $(\mathrm{n}=2,450)$ were from a study conducted to evaluate the effects of lasalocid supplementation on dairy cows (Erickson et al., 2000); however, lasalocid supplementation did not affect feed consumption $(P>$ 0.10). Each of 35 multiparous Holstein cows was fed a TMR for their first 70 DIM. The diet was 33\% corn silage, $17 \%$ coarsely chopped alfalfa hay, and $50 \%$ concentrate mix (ground shelled corn and soybean meal based) on a DM basis. Feed was offered twice daily to achieve $10 \%$ orts on an as-fed basis at 1100 and 1630 $\mathrm{h}$. The trial was conducted over a 200 -d period between February and August. Daily DMI and milk yield data were obtained, and BW and milk composition were determined weekly.

The New Hampshire dataset ( $\mathrm{n}=2,380$ ) was from a trial designed to study lysine and methionine nutrition during late gestation and early lactation (Wasserstorm, 1996). Data used were from the control cows. Each of 34 Holstein cows was fed a TMR for their first 70 DIM. The TMR was corn-based, and soybean products provided supplemental protein. Data again consisted of daily DMI and milk yields and weekly BW and milk compositions.

The Pennsylvania dataset $(\mathrm{n}=3,717)$ was from a study conducted to compare the effects of feeding diets of varied ruminal carbohydrate degradability to transition cows based on their DMI, blood metabolites, lactation performance, ruminal fermentation, and digesta kinetics (Dann et al., 1999). All 59 cows were fed TMR, containing either cracked corn or steam-flaked corn, once daily. The DMI data were for the first 63 DIM and were not affected by treatment $(P>0.10)$.

Illinois data were used for model development, and New Hampshire and Pennsylvania datasets were used for model validation and evaluation. For comparison with the NRC (2001) model, Illinois and New Hamphire 
datasets were used, as production data for individual cows were only available for these 2 locations.

\section{Description of Postpartum Changes in DMI}

Daily DMI data for each cow from the Illinois dataset were plotted against DIM and were visually evaluated for the shape of the curve. Based on the shape of the curve, various exponential and linear functions were fitted to the daily DMI vs. DIM data for each cow to describe the gradual increase in feed consumption postpartum. Based on coefficient of determination values and visual examination of plots (simulated and observed daily DMI against DIM and residual vs. predicted) for each cow, it was concluded that the best fitting function for a majority of cows $(86 \%)$ was the exponential model

$$
\operatorname{DMI}(\mathrm{t})=\mathrm{a}-\mathrm{b} \mathrm{e}^{-\mathrm{ct}}
$$

where $\operatorname{DMI}(\mathrm{t})$ = daily DMI for corresponding DIM, a = asymptotic maximum DMI, $b=$ potential increase in DMI, $\mathrm{c}=$ fractional rate of increase of DMI with DIM, and $\mathrm{t}=\mathrm{DIM}$. Although a similar equation has been used to describe postpartum changes in DMI and DM in the reticulorumen (Rémond, 1988), neither the biological relevance of its parameters nor its suitability compared with alternative models was discussed.

A linear model fit best for $14 \%$ of the cows. The linear model contained the minimum DMI as the intercept and the rate of change in DMI as the slope with DIM.

The exponential model was fitted (Sherrod, 2000) to daily DMI data of each cow for model evaluation and validation. The exponential model parameter estimates were tested for location effect (SAS, 1997). Weekly mean DMI were also calculated and fitted to both the exponential and NRC (2001) models for comparison.

\section{Statistical Criteria for Model Validation, Evaluation, and Comparison}

A wide range of model validation methods (subjective assessment, visual techniques, deviance measures, and statistical tests) have been proposed and used in many different fields of study. Residuals (difference between observed and predicted) vs. predicted plots are widely used in statistical diagnostics (Draper and Smith, 1996), but Mayer and Butler (1993) recommended observed vs. predicted graphs over these plots, as these can be visualized directly and easily from the graph. Therefore, both types of plots were used for visual evaluation.

To evaluate model accuracy, most of the commonly used deviance measures were utilized [mean absolute error (MAE), mean square prediction error (MSPE), and square root of MSPE (RMSE) as proposed by Picard and Cook (1984), also known as mean prediction error (MPE)]. The MSPE criterion has often been used in feed intake prediction comparison studies (Neal et al., 1984; Rook et al., 1991; Kabuga, 1992; Fuentes-Pila et al., 1996; Roseler et al., 1997b; Fuentes-Pila et al., 2003; Hayirli et al., 2003) and to validate published equations for intake prediction (Vadiveloo and Holmes, 1979; Rook et al., 1991; Roseler et al., 1997a). Bibby and Toutenburg (1977) defined MSPE as $\Sigma\left(\mathrm{O}_{\mathrm{i}}-\mathrm{P}_{\mathrm{i}}\right)^{2} / \mathrm{n}$, where $\mathrm{n}=$ number of pairs of observed $(\mathrm{O})$ and predicted (P) DMI values being compared. Schaeffer (1980) defined MAE as $\left(\Sigma\left|\mathrm{O}_{\mathrm{i}}-\mathrm{P}_{\mathrm{i}}\right|\right) / \mathrm{n}$. Additionally, relative prediction error (RPE), which is MAE as a proportion of observed mean values, was used to determine precision and reproducibility of prediction.

Regression analysis of observed vs. predicted data is also a widely used statistical test in model validation (Draper and Smith, 1996; Hayirli et al., 2003). To conform to statistical assumptions, it is usual to take the observations as the ordinate, and model predictions as the abscissa. Regression analyses produce a number of useful statistics; coefficient of determination, an indicator of degree of fit; slope; and variances can be used to estimate components of MSPE. The MSPE can be expressed as a sum of 3 components (Bibby and Toutenburg, 1977). The first is squared mean bias of the prediction, the difference between the means of observed and predicted intake. The second is the line bias, a product of the variance of predicted intakes and the square of the deviation from unity of the slope of regression of observed on predicted data. The third component is the random variation around the regression line, a product of the variance of observed data and the deviation from unity of the coefficient of determination of the regression of observed on predicted data. In validation of a regression equation with independent datasets, mean bias can be used to test robustness of the model, and line bias can test underlying inadequacies in model structure. In addition to mean bias, mean proportional bias is calculated as the slope of a regression of the predicted data on observed data with a zero intercept. Mean proportional bias $<1$ indicates an underprediction across the range of the observed values, and a value $>1$ indicates an overprediction (Roseler et al., 1997a). A nonlinear regression analysis program (Sherrod, 2000) estimated the coefficient of determination, which was used as a model fit criterion. In addition, modeling efficiency (ME), a dimensionless statistic that directly relates model predictions to observed data (Loague and Green, 1991) was utilized. The ME is an extension of the $\mathrm{R}^{2}$ statistic for the class of nonlinear regression models (Mayer and Butler, 1993). Modeling efficiency 
Table 2. Parameter estimates for the exponential model ${ }^{1}$ fitted to daily DMI of individual cows

\begin{tabular}{|c|c|c|c|c|}
\hline \multirow[b]{2}{*}{ Item } & \multicolumn{4}{|c|}{ Cow group ${ }^{2}$} \\
\hline & $\begin{array}{l}\text { All } \\
\text { cows }\end{array}$ & Illinois & $\begin{array}{l}\text { New } \\
\text { Hampshire }\end{array}$ & Pennsylvania \\
\hline \multicolumn{5}{|c|}{ Asymptotic DMI (a), kg } \\
\hline Mean & 26.4 & 27.6 & 27.5 & 25.2 \\
\hline SEM & 0.5 & 1.2 & 0.7 & 0.6 \\
\hline CV & 17.7 & 21.7 & 12.4 & 16.5 \\
\hline Minimum & 17.8 & 17.8 & 22.7 & 18.4 \\
\hline Maximum & 44.5 & 41.1 & 39.3 & 44.5 \\
\hline \multicolumn{5}{|c|}{ Potential increase in DMI (b), kg } \\
\hline Mean & 13.9 & 16.1 & 13.3 & 12.9 \\
\hline SEM & 0.6 & 1.3 & 1.1 & 0.8 \\
\hline CV & 42.1 & 40.6 & 40.8 & 41.8 \\
\hline Minimum & 4.4 & 5.4 & 6.3 & 4.4 \\
\hline Maximum & 34.8 & 31.3 & 25.5 & 34.8 \\
\hline \multicolumn{5}{|c|}{ Fractional rate of increase in DMI (c), /d } \\
\hline Mean & 0.06 & 0.05 & 0.07 & 0.06 \\
\hline SEM & 0.004 & 0.005 & 0.010 & 0.006 \\
\hline $\mathrm{CV}$ & 70.3 & 58.7 & 70.3 & 70.1 \\
\hline Minimum & 0.01 & 0.01 & 0.01 & 0.01 \\
\hline Maximum & 0.25 & 0.11 & 0.23 & 0.25 \\
\hline \multicolumn{5}{|c|}{ Proportion of variance explained, $R^{2}$} \\
\hline Mean & 0.64 & 0.74 & 0.49 & 0.67 \\
\hline SEM & 0.02 & 0.03 & 0.03 & 0.03 \\
\hline $\mathrm{CV}$ & 30.8 & 24.1 & 35.2 & 25.8 \\
\hline Minimum & 0.20 & 0.22 & 0.20 & 0.21 \\
\hline Maximum & 0.93 & 0.93 & 0.79 & 0.91 \\
\hline
\end{tabular}

${ }^{1} \mathrm{DMI}(\mathrm{t})=\mathrm{a}-\mathrm{b} \mathrm{e}^{-\mathrm{ct}}$, where $\mathrm{DMI}(\mathrm{t})=$ daily DMI for corresponding DIM, a = asymptotic maximum DMI, $\mathrm{b}=$ potential increase in DMI, $\mathrm{c}=$ fractional rate of increase in DMI with DIM, and $\mathrm{t}=$ DIM.

${ }^{2}$ Illinois (Erickson et al., 2000), New Hampshire (Wasserstorm, 1996), and Pennsylvania (Dann et al., 1999).

is defined as $1-\Sigma\left(\mathrm{O}_{\mathrm{i}}-\mathrm{P}_{\mathrm{i}}\right)^{2} / \Sigma\left(\mathrm{O}_{\mathrm{i}}-\mathrm{O}_{\mathrm{m}}\right)^{2}$, where $\mathrm{O}_{\mathrm{m}}=$ mean of observed data. The calculated ME is an overall indication of goodness of fit; values $\sim 1$ indicate a "near perfect" model.

\section{RESULTS AND DISCUSSION}

\section{Description of Postpartum Changes in DMI}

The best-fitted function for $86 \%$ of the individual cow DMI was the exponential model. The linear model was only used for 5 of 35 Illinois cows and 4 of 34 New Hampshire cows, and it explained 49 and $45 \%$ of the variation in daily DMI for Illinois and New Hampshire cows, respectively.

\section{Exponential Model Evaluation and Validation}

The exponential model, fitted to the individual cow daily DMI data, explained an average of $74 \%$ of the total variation in daily DMI for Illinois data, $49 \%$ of the variation for New Hampshire data, $67 \%$ of the variation for Pennsylvania data, and $64 \%$ of the variation overall (Table 2). This model contains 3 parameters, namely, asymptotic DMI in kilograms (a), potential for increase in DMI in kilograms (b), and fractional rate of increase in DMI (c). All 3 parameters have straightforward biological interpretations compared with other prediction equations containing polynomial or logarithmic terms, and their estimates are given in Table 2. Data for individual cows were further evaluated only if all 3 parameters in the model were significant $(P<$ 0.05 ). These parameters could be useful in diet evaluation and genetic selection. Chase (1993) suggested that the rate of increase in DMI in early lactation (estimated as $\mathrm{c}$ in the exponential model) might be the primary determinant of energy intake and balance.

The parameters estimated for cows from 3 locations were not significantly different $(P>0.05)$. Numerically, Illinois cows tended to have higher asymptotic and potential increases in DMI and comparatively lower fractional rates of increase in DMI (Table 2). These numerical differences in the parameters of the model could result from differences in the body condition, peak milk yield, parity, bST treatment, body size, and diets across locations (Neal et al., 1984; Roseler et al., 1997b). Mean values for 3.5\% FCM yield (Table 1) and fractional rate of increase in DMI (Table 2) suggested a linear relationship between them; however, the statistical significance of this relationship could not be confirmed by analyzing Illinois and New Hampshire datasets. Roseler et al. 

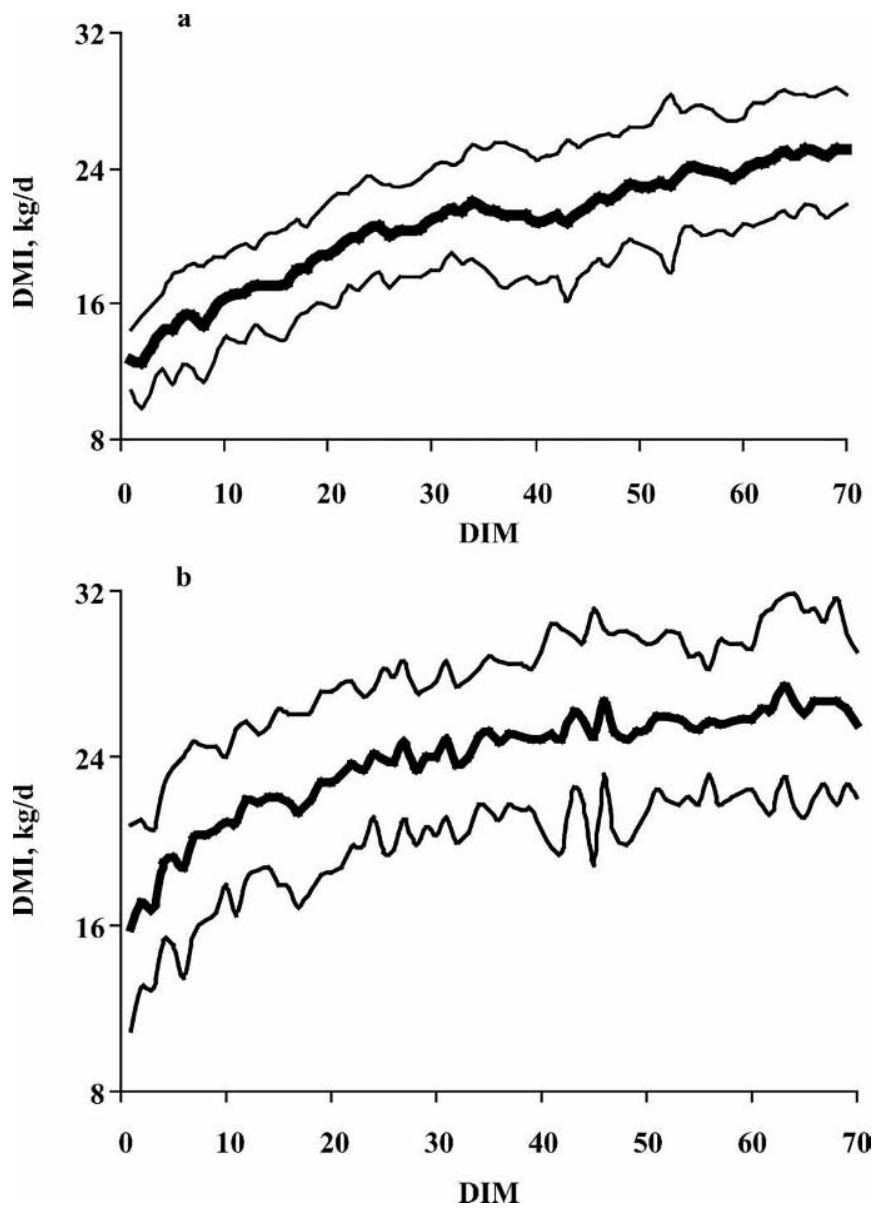

Figure 1. Herd average daily DMI least squares mean (thick line) along with standard error (thin lines) values for a) Illinois (Erickson et al., 2000) or b) New Hampshire (Wasserstorm, 1996) cows.

(1997b) reported a correlation between milk yield and DMI (0.67 and 0.61 for control and bST-treated multiparous cows) and suggested grouping cows based on parity and bST treatment (group size $\sim 30$ ).

Most previous models of DMI in early lactation were fitted to weekly mean DMI values that reduced the large variations present in daily DMI data (Figure 1, $a$ and b) and may erroneously increase coefficients of determination. Coulon (1981) reported ranges and coefficients of variation for differences between individual cow DMI of $2.7 \mathrm{~kg}$ and $17 \%$ for wk 1 of lactation and $2.4 \mathrm{~kg}$ and $12 \%$ for wk 4 of lactation. Ingvartsen et al. (1992) attributed $66.5 \%$ of the total variation in feed intake of an individual cow to day-to-day variation and only $2.5 \%$ to week of lactation. Variation in the feed intake of cows in early lactation might also have important health consequences. McGuffey et al. (1997) reported that a $1 \%$ increase in the coefficient of variation of DMI in the first 21 DIM was associated with a $4 \%$ increase $(P<0.001)$ in the odds of an adverse health incident (calving-related, metabolic, or digestive disorder). Therefore, use of weekly mean data ignores most of the variation in DMI and could confound efforts to reduce the odds of health problems. To illustrate this point, the exponential model explained $98 \%$ of the variation in daily DMI when Illinois data were averaged across cows; parameter estimates were $\mathrm{a}=25.8, \mathrm{~b}=$ 14.1 , and $\mathrm{c}=0.04$. Clearly, averages over time remove much of the cow-to-cow variation, although most DMI prediction equations are based on weekly or herd mean values of variables included in the models.

The exponential model was further evaluated and validated by comparing the fit of the function to individual cow data through graphical, deviance measure, and statistical test methods. Residuals vs. predicted plots are widely used (Figure 2, a to d; Draper and Smith, 1996). These graphs indicate the spread of the variation in the prediction with respect to actual DMI. Mayer and Butler (1993) recommended observed vs. predicted over residuals vs. predicted plots, as these can be visualized directly and easily from the Figure 3 (a to d). These figures demonstrate the accuracy and robustness of the exponential model.

The prediction accuracy of the model was measured by estimating MSPE, MAE, RPE, RMSE or MPE, and ME for each cow, and results are reported in Table 3. For Illinois cows, mean prediction accuracy and $\mathrm{ME}$ were better $(\mathrm{RMSE}=1.9 \mathrm{~kg} / \mathrm{d}, \mathrm{RPE}=7 \%$, and $\mathrm{ME}=$ $74 \%$ ) compared with New Hampshire cows (RMSE = $2.9 \mathrm{~kg} / \mathrm{d}, \mathrm{RPE}=9 \%$, and $\mathrm{ME}=49 \%$ ). Prediction accuracies for Pennsylvania cows $(\mathrm{RMSE}=1.8 \mathrm{~kg} / \mathrm{d}, \mathrm{RPE}=$ $7 \%$, and $\mathrm{ME}=58 \%$ ) were close to the overall mean values. The lowest prediction accuracy was noted for New Hampshire cows, which was associated with a lower ME value (49\%).

Predicted values for each cow were combined, first by location and then overall, and evaluated to examine prediction accuracy and robustness of the model (Table 3). A low MPE was estimated for Illinois cows $(2 \mathrm{~kg} / \mathrm{d})$ as compared with $2.9 \mathrm{~kg} / \mathrm{d}$ for New Hampshire cows. The RPE was $10 \%$ for the combined dataset, and 9, 12, and $10 \%$ for Illinois, New Hampshire, and Pennsylvania cows, respectively. Fuentes-Pila et al. (1996) considered RPE $<10 \%$ satisfactory for prediction of DMI, between 10 and $20 \%$ as relatively good or acceptable for prediction of DMI, and $>20 \%$ as lacking in robustness. Daily DMI datasets for cows fed 3 different diets at 3 different locations suggested that the exponential model of the present study satisfactorily predicted DMI. Fuentes-Pila et al. (1996) considered feed intake prediction models robust if overall RPE was $\leq 20 \%$. They evaluated 7 different feed intake prediction equations and concluded that none of the 7 equations was able to predict individual cow DMI with a prediction error con- 


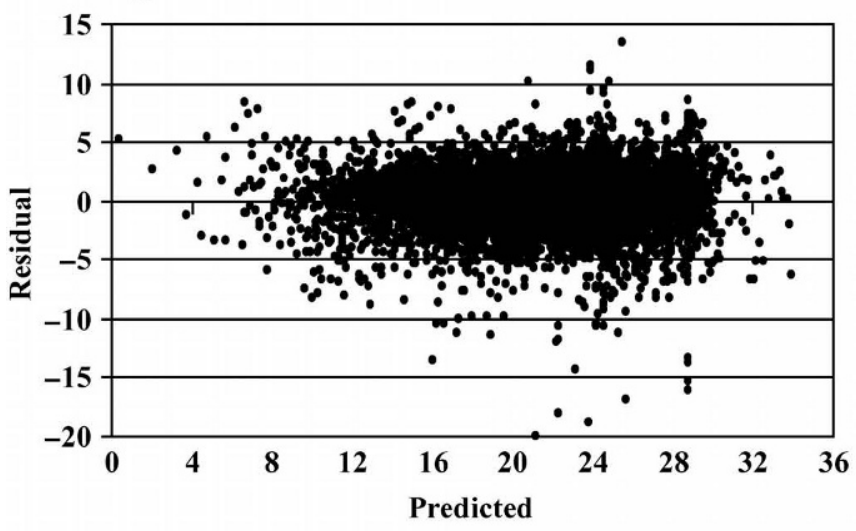

c

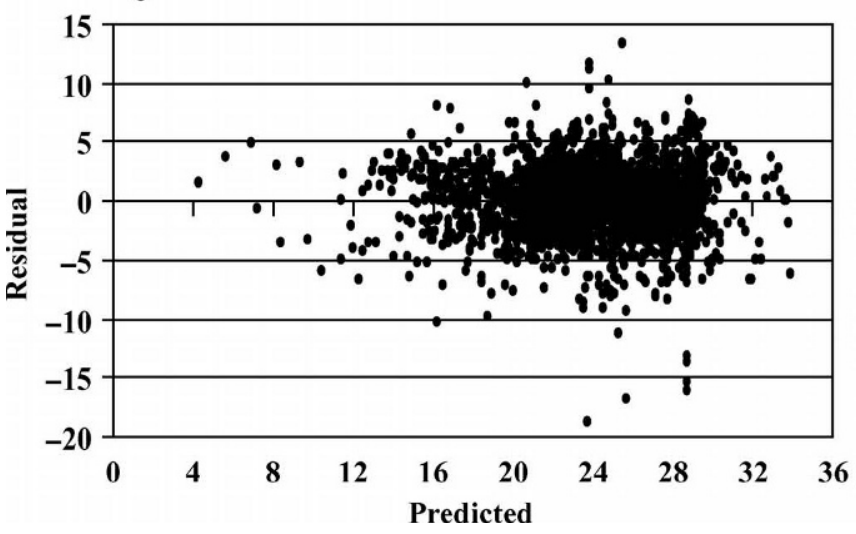

b

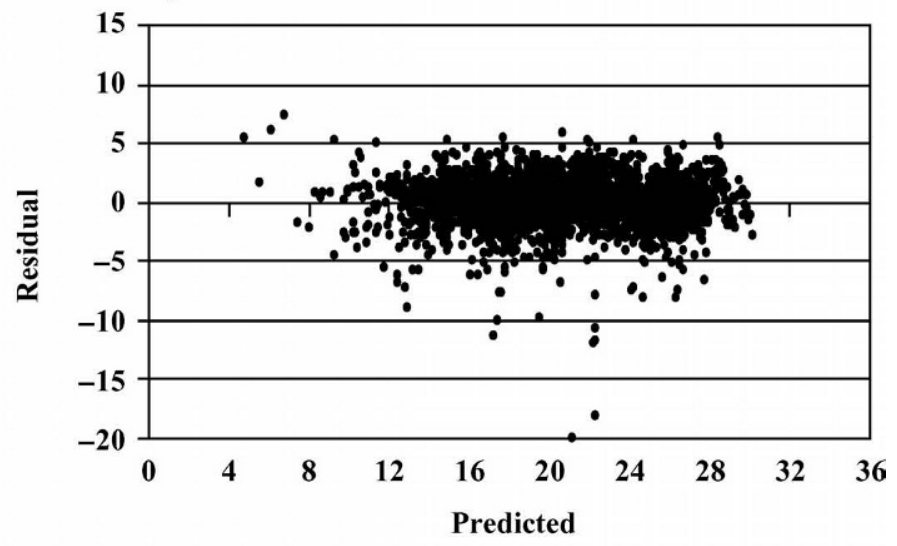

d

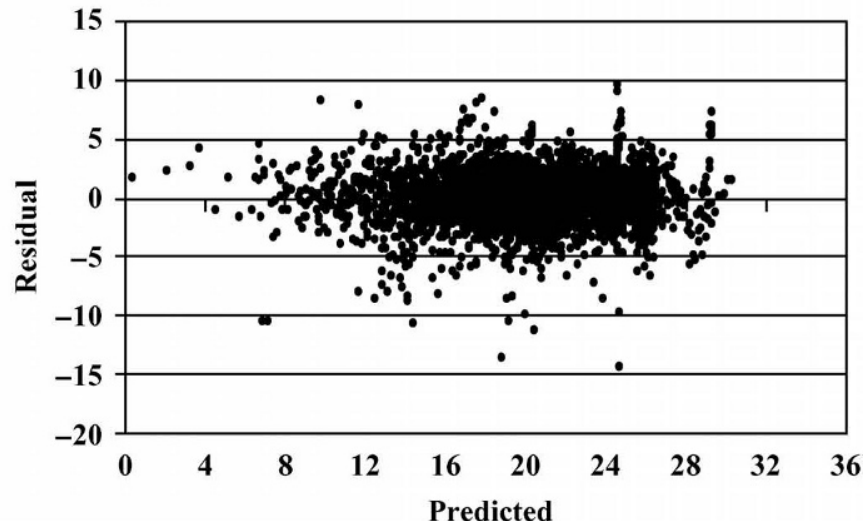

Figure 2. Relationship between residual (predicted minus observed) and predicted DMI (k/d) for a) all, b) Illinois (Erickson et al., 2000), c) New Hampshire (Wasserstorm, 1996), or d) Pennsylvania (Dann et al., 1999) cows.

sistently within $20 \%$ of the observed mean DMI. Overall prediction error for the exponential model was consistently within the $10 \%$ range of the observed mean DMI.

Accuracy of prediction using the exponential model was further evaluated by calculating the proportions of the predicted values within various percentages of the actual DMI (Table 4). It was observed that, overall, $9 \%$ of the predicted DMI were within $1 \%$ of the observed DMI and $71 \%$ were within $10 \%$ of the actual DMI for any particular day. The various proportions for different percentages were very similar for Illinois and Pennsylvania cows. The overall and individual location MSPE values were much lower for the exponential model in this study (Table 4) than the values reported by Fuentes-Pila et al. (1996) and Roseler et al. (1997a) for other DMI prediction equations.

The MSPE values for all groups of cows were further partitioned into weekly estimates to examine the variability in MSPE by week (Table 5). The exponential model predicted DMI with the best precision during wk 2 to 5 (MSPE $=3.2,6.6$, and $3.9 \mathrm{~kg}^{2} / \mathrm{d}^{2}$ for Illinois, New Hampshire, and Pennsylvania data, respectively). The model prediction was least precise during wk 6 to 8 of lactation, particularly during wk 7 of lactation, as compared with other weeks in early lactation.

High variability and lack of precision during wk 6 to 8 postpartum may result from high demand for energy because of rapid increases in milk production of some cows that reach peak yield faster (Roseler et al., 1997a). The correlation between milk yield and DMI (0.67; Roseler et al., 1997b) may accelerate the rate of increase in DMI. Because high-concentrate diets are fed during early lactation, sudden increases in DMI may lower ruminal $\mathrm{pH}$, and changes in rumen dynamics may cause subacute or acute rumen acidosis that can depress DMI in some high-producing cows. Consequently, these metabolic conditions may cause fluctuation in daily DMI (Cooper et al., 1999).

Compared with the MSPE $\left(5.06 \mathrm{~kg}^{2} / \mathrm{d}^{2}\right)$ for the exponential model, Fuentes-Pila et al. (1996) reported very high MSPE estimates (up to $58.9 \mathrm{~kg}^{2} / \mathrm{d}^{2}$ ) for the first 8 wk of lactation. Roseler et al. (1997a) reported even higher $\left(71.5 \mathrm{~kg}^{2} / \mathrm{d}^{2}\right)$ MSPE for Kertz et al. (1991) multiple regression equations for early lactation cows (wk 1 

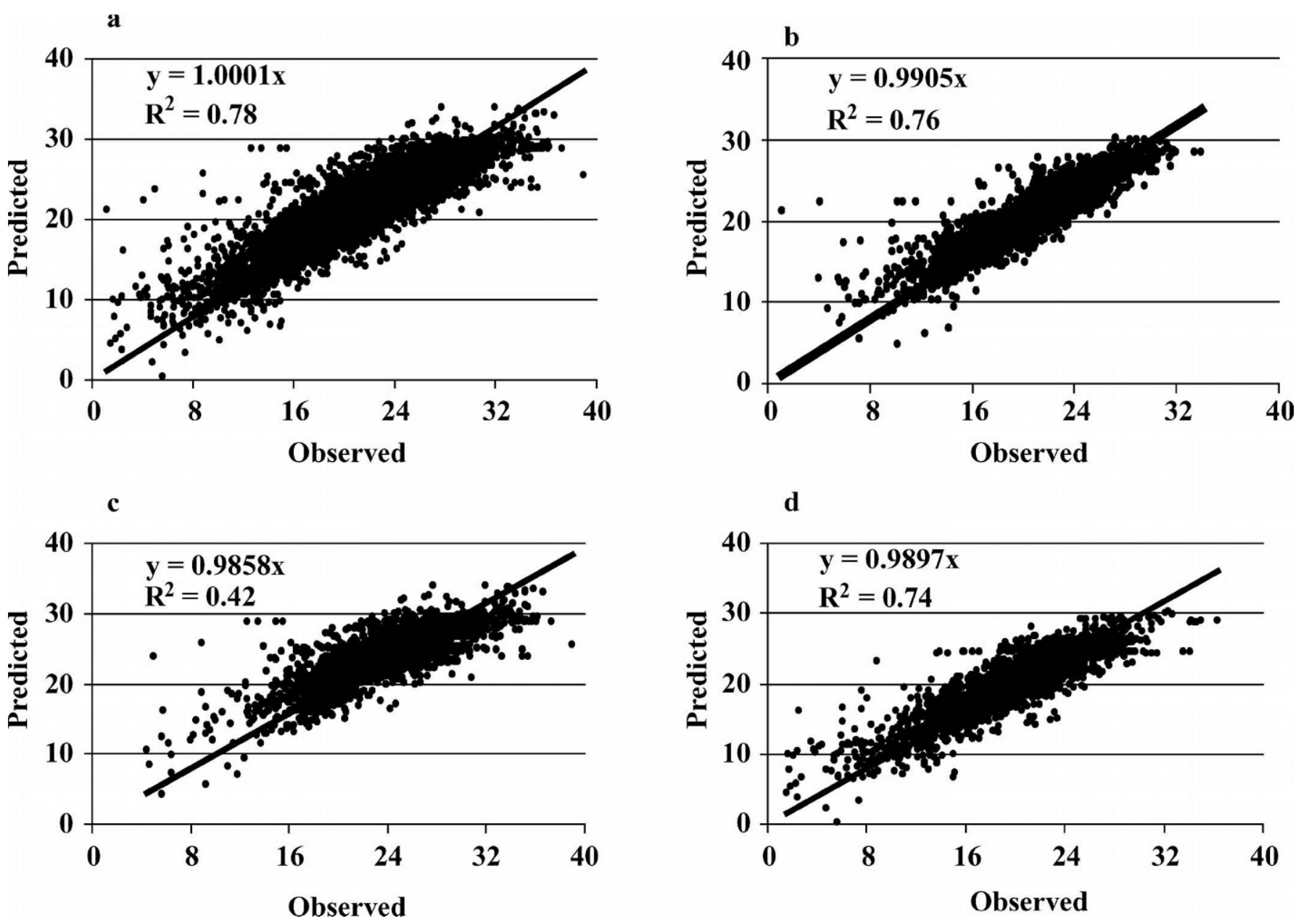

Figure 3. Relationship between predicted and observed DMI (kg/d) for a) overall, b) Illinois (Erickson et al., 2000), c) New Hampshire (Wasserstorm, 1996), or d) Pennsylvania (Dann et al., 1999) cows.

to 9). In both studies, highest inaccuracy of prediction occurred during the early lactation period.

An effect of parity on MSPE was also noted in previous studies (Neal et al., 1984; Roseler et al., 1997a). Roseler et al. (1997a) also reported 2-fold higher MSPE for multiparous cows as compared with primiparous cows. These differences were attributed to less variability in BW and milk yield for primiparous cows than for multiparous cows (Neal et al., 1984; Roseler et al., 1997a).

The robustness and precision of the exponential model can easily be demonstrated from its accuracy of prediction even for individual cow daily DMI data during early lactation across different locations and diets $\left(\mathrm{MSPE}=5.06 \mathrm{~kg}^{2} / \mathrm{d}^{2}\right)$.

\section{Components of MSPE for Daily DMI Data}

The partition of MSPE into 3 component parts (mean bias, line bias, and random variation) suggests that random variation values appear to be the major causes of inaccuracy in the prediction of daily DMI (Table 6). The random variation component of the MSPE is a function of the coefficient of variation for regression of observed on predicted DMI $\left(\mathrm{R}^{2}\right)$ and variance $\left(\mathrm{S}_{\mathrm{O}}{ }^{2}\right)$ of observed data $\left[\left(1-\mathrm{R}^{2}\right) \mathrm{S}_{\mathrm{O}}{ }^{2}\right]$ (Fuentes-Pila et al., 1996). Yungblut et al. (1981) considered $\mathrm{R}^{2}$ values $<0.50$ as indicative that a DMI prediction equation was not explaining a large proportion of actual variation of DMI in a data file. In this study, higher values for random variation were associated with larger $\mathrm{S}_{\mathrm{O}}{ }^{2}$ of daily DMI rather than $\left(1-R^{2}\right)$ part of the random variation. The mean $R^{2}$ values for overall, Illinois, New Hampshire, and Pennsylvania groups of data were $0.78,0.81,0.63$, and 0.79 , respectively. Comparatively lower $\mathrm{R}^{2}$ values for New Hampshire data may be related to more variation in daily feed intake (Table 6; Figure 1b).

High values were observed for the variance of actual daily DMI (21.2 to $24.2 \mathrm{~kg}^{2} / \mathrm{d}^{2}$ ) as compared with the 
Table 3. Prediction accuracy of daily DMI by the exponential model ${ }^{1}$

\begin{tabular}{|c|c|c|c|c|}
\hline \multirow[b]{2}{*}{ Measure $^{3}$} & \multicolumn{4}{|c|}{ Cow group ${ }^{2}$} \\
\hline & $\begin{array}{l}\text { All } \\
\text { cows }\end{array}$ & Illinois & $\begin{array}{l}\text { New } \\
\text { Hampshire }\end{array}$ & Pennsylvania \\
\hline \multicolumn{5}{|c|}{ MSPE, $\mathrm{kg}^{2} / \mathrm{d}^{2}$} \\
\hline Mean & 5.06 & 3.89 & 8.63 & 3.48 \\
\hline SD & 3.44 & 2.54 & 3.56 & 1.82 \\
\hline CV & 0.68 & 0.65 & 0.41 & 0.52 \\
\hline Minimum & 1.55 & 1.55 & 3.86 & 1.59 \\
\hline Maximum & 21.62 & 14.68 & 21.62 & 10.07 \\
\hline \multicolumn{5}{|l|}{$\mathrm{MAE}, \mathrm{kg} / \mathrm{d}$} \\
\hline Mean & 1.65 & 1.46 & 2.22 & 1.40 \\
\hline SD & 0.50 & 0.33 & 0.39 & 0.34 \\
\hline CV & 0.30 & 0.23 & 0.18 & 0.24 \\
\hline Minimum & 0.97 & 0.97 & 1.64 & 1.01 \\
\hline Maximum & 3.29 & 2.55 & 3.29 & 2.54 \\
\hline \multicolumn{5}{|c|}{ RPE, proportion } \\
\hline Mean & 0.08 & 0.07 & 0.09 & 0.07 \\
\hline SD & 0.02 & 0.02 & 0.02 & 0.02 \\
\hline CV & 0.27 & 0.25 & 0.18 & 0.27 \\
\hline Minimum & 0.05 & 0.05 & 0.07 & 0.05 \\
\hline Maximum & 0.13 & 0.12 & 0.13 & 0.12 \\
\hline \multicolumn{5}{|l|}{ RMSE, $\mathrm{kg} / \mathrm{d}$} \\
\hline Mean & 2.14 & 1.90 & 2.89 & 1.82 \\
\hline SD & 0.68 & 0.52 & 0.56 & 0.44 \\
\hline CV & 0.32 & 0.27 & 0.19 & 0.24 \\
\hline Minimum & 1.24 & 1.24 & 1.97 & 1.26 \\
\hline Maximum & 4.65 & 3.83 & 4.65 & 3.17 \\
\hline \multicolumn{5}{|l|}{$\mathrm{ME}, \%$} \\
\hline Mean & 60 & 74 & 49 & 58 \\
\hline SD & 22 & 18 & 17 & 23 \\
\hline CV & 37 & 24 & 35 & 39 \\
\hline Minimum & 1 & 22 & 20 & 1 \\
\hline Maximum & 93 & 93 & 79 & 90 \\
\hline
\end{tabular}

${ }^{1} \mathrm{DMI}(\mathrm{t})=\mathrm{a}-\mathrm{b} \mathrm{e}^{-\mathrm{ct}}$, where $\mathrm{DMI}(\mathrm{t})=$ daily DMI for corresponding DIM, $\mathrm{a}=$ asymptotic maximum DMI, $\mathrm{b}=$ potential increase in DMI, $\mathrm{c}=$ fractional rate of increase of DMI with DIM, and $\mathrm{t}=$ DIM.

${ }^{2}$ Illinois (Erickson et al., 2000), New Hampshire (Wasserstorm, 1996), and Pennsylvania (Dann et al., 1999).

${ }^{3} \mathrm{MSPE}=$ Mean square prediction error, MAE $=$ mean absolute error, $\mathrm{RPE}=\mathrm{MAE}$ as a proportion of observed mean values, $\mathrm{RMSE}=$ relative mean square error (square root of MSPE), and ME = modeling efficiency.

Table 4. Proportion of predicted values within various percentages of observed daily DMI using the exponential model ${ }^{1}$

\begin{tabular}{lrrcc}
\hline & \multicolumn{4}{c}{ Cow group $^{2}$} \\
\cline { 2 - 5 } $\begin{array}{l}\text { Measure } \\
\text { within }\end{array}$ & All cows & Illinois & $\begin{array}{l}\text { New } \\
\text { Hampshire }\end{array}$ & Pennsylvania \\
\hline \multirow{2}{*}{$1 \%$} & 0.09 & 0.10 & 0.08 & 0.10 \\
$2 \%$ & 0.18 & 0.19 & 0.15 & 0.19 \\
$3 \%$ & 0.26 & 0.28 & 0.22 & 0.28 \\
$5 \%$ & 0.42 & 0.44 & 0.36 & 0.45 \\
$6 \%$ & 0.49 & 0.52 & 0.43 & 0.52 \\
$8 \%$ & 0.62 & 0.65 & 0.54 & 0.64 \\
$10 \%$ & 0.71 & 0.74 & 0.63 & 0.74 \\
$\mathrm{n}$ & 8,360 & 2,450 & 2,261 & 3,649 \\
\hline
\end{tabular}

${ }^{1} \mathrm{DMI}(\mathrm{t})=\mathrm{a}-\mathrm{b} \mathrm{e} \mathrm{e}^{-\mathrm{ct}}$, where DMI $(\mathrm{t})=$ daily DMI for corresponding DIM, $\mathrm{a}=$ asymptotic maximum DMI, $\mathrm{b}=$ potential increase in DMI, $\mathrm{c}=$ fractional rate of increase of DMI with DIM, and $\mathrm{t}=\mathrm{DIM}$.

${ }^{2}$ Illinois (Erickson et al., 2000), New Hampshire (Wasserstorm, 1996), and Pennsylvania (Dann et al., 1999).
Table 5. Comparison of mean square prediction error (MSPE) by week for the daily DMI of Illinois (Erickson et al., 2000), New Hampshire (Wasserstorm, 1996), and Pennsylvania (Dann et al., 1999) cows

\begin{tabular}{llll}
\hline & \multicolumn{3}{c}{ MSPE } \\
\cline { 2 - 4 } $\begin{array}{l}\text { Week of } \\
\text { lactation }\end{array}$ & Illinois & $\begin{array}{l}\text { New } \\
\text { Hampshire }\end{array}$ & Pennsylvania \\
\hline & & & \\
& 3.9 & 9.0 & \\
1 & 3.1 & 5.4 & 4.6 \\
2 & 3.2 & 7.6 & 3.7 \\
3 & 2.8 & 7.0 & 3.7 \\
4 & 3.8 & 6.3 & 4.2 \\
5 & 6.4 & 9.5 & 4.2 \\
6 & 6.8 & 14.0 & 4.6 \\
7 & 5.6 & 8.6 & 5.2 \\
8 & 3.7 & 8.6 & 4.3 \\
9 & 3.3 & 8.3 & 4.9 \\
10 & 3.2 & 6.6 & 3.9 \\
2 to 5 & 6.3 & 10.7 & 4.7 \\
6 to 8 & 3.2 & 7.2 & 4.1 \\
1 to 4 & 3.5 & 9.6 & 4.6 \\
5 to 8 & 4.2 & 8.4 & 4.9 \\
9 to $10^{1}$ & & & \\
\hline
\end{tabular}

${ }^{1}$ Value of wk 9 only for Pennsylvania cows.

values observed with weekly mean $\mathrm{DMI}$ in the present experiment (Table 5) and by others (Fuentes-Pila et al., 1996; Roseler et al., 1997a). The use of daily DMI data might be the cause of the high variance. The use of weekly or group mean data, as in previous studies (Fuentes-Pila et al., 1996; Roseler et al., 1997a), could significantly reduce the MSPE by erroneously removing important day-to-day and cow-to-cow variation in DMI (Coulon, 1981; Ingvartsen et al., 1992; Mason and Kennelly, 2001).

The mean and line bias values were almost zero for all datasets (Table 6). These results further suggest a high level of precision in the prediction of daily DMI with the exponential model. Mean proportion bias, a measure of under- and overprediction over the range of the observed values (Rayburn and Fox, 1993), agrees with the values of mean and line bias. Unlike previous model evaluation studies that reported very high [35\% (Roseler et al., 1997a) and 22\% (Fuentes-Pila et al., 1996)] mean proportion bias, values were near zero for all datasets in this experiment (Table 6). Values for the MSPE components and mean proportion bias further confirm the accuracy of prediction, adequacy of the structure, and robustness of the exponential model (Rook et al., 1991).

A model may be considered robust and less risky for practical use if it has a satisfactory level of accuracy for most datasets (RPE $\leq 10 \%)$ rather than high accuracy for some datasets and poor accuracy for others (Fuentes-Pila et al., 1996). The exponential model prediction accuracy of daily DMI was consistent for all datasets $(\mathrm{RPE}<10 \%)$, suggesting that it is robust. The 
Table 6. Prediction accuracy and mean square prediction error components of the exponential model ${ }^{1}$ for daily DMI of Illinois (Erickson et al., 2000), New Hampshire (Wasserstorm, 1996), and Pennsylvania (Dann et al., 1999) cows

\begin{tabular}{|c|c|c|c|c|}
\hline $\begin{array}{l}\text { Week of } \\
\text { lactation }\end{array}$ & $\begin{array}{l}\text { Mean } \\
\text { bias }^{2}\end{array}$ & $\begin{array}{l}\text { Line } \\
\text { bias }^{3}\end{array}$ & $\begin{array}{l}\text { Random } \\
\text { variation }^{4}\end{array}$ & $\begin{array}{l}\text { Mean } \\
\text { proportional } \text { bias }^{5}\end{array}$ \\
\hline \multicolumn{5}{|l|}{ All cows ${ }^{6}$} \\
\hline wk 1 to 10 & 0.010 & 0.000 & 5.324 & 0.000 \\
\hline wk 7 & 0.010 & 0.094 & 7.912 & -0.001 \\
\hline \multicolumn{5}{|l|}{ Illinois cows } \\
\hline wk 1 to 10 & 0.000 & 0.000 & 4.199 & 0.000 \\
\hline wk 7 & -0.680 & 0.039 & 6.258 & 0.028 \\
\hline \multicolumn{5}{|c|}{ New Hampshire cows } \\
\hline wk 1 to 10 & 0.000 & 0.000 & 8.399 & 0.000 \\
\hline wk 7 & 0.180 & 0.267 & 13.765 & -0.005 \\
\hline \multicolumn{5}{|c|}{ Pennsylvania cows } \\
\hline wk 1 to 9 & 0.010 & 0.000 & 4.452 & 0.000 \\
\hline wk 7 & 0.320 & 0.175 & 4.830 & -0.016 \\
\hline
\end{tabular}

${ }^{1} \mathrm{DMI}(\mathrm{t})=\mathrm{a}-\mathrm{b} \mathrm{e}^{-\mathrm{ct}}$, where $\mathrm{DMI}(\mathrm{t})=$ daily DMI for corresponding DIM, a = asymptotic maximum DMI, $\mathrm{b}=$ potential increase in DMI, $\mathrm{c}=$ fractional rate of increase of DMI with DIM, and $\mathrm{t}=$ DIM.

${ }^{2}$ Mean bias $=$ observed $(\mathrm{O})$ minus predicted $(\mathrm{P})$ mean DMI $(\mathrm{kg} / \mathrm{d})$.

${ }^{3}$ Line bias $=(1-b)^{2} \times S_{p}^{2}$, where $\mathrm{b}$ is the slope of the regression of $\mathrm{O}$ on $\mathrm{P}$ and $\mathrm{S}_{\mathrm{p}}^{2}=$ variance of the predicted DMI $\left(\mathrm{kg} / \mathrm{d}^{2}\right)$.

${ }^{4}$ Random variation $=\left(1-R^{2}\right) \times S^{2}{ }_{0}$, where $R^{2}$ is the coefficient of determination for the regression of $\mathrm{O}$ on $\mathrm{P}$ and $\mathrm{S}_{\mathrm{O}}^{2}=$ variance of the observed DMI $\left(\mathrm{kg} / \mathrm{d}^{2}\right)$.

${ }^{5}$ Mean proportion bias = deviation from unity, expressed as a percentage of one of the slope of a regression analysis of $\mathrm{P}$ on $\mathrm{O}$ with the intercept forced to be zero.

${ }^{6}$ Data for wk 10 were only from Illinois and New Hampshire cows.

exponential model, therefore, could reasonably be used for prediction of daily DMI.

\section{Comparison with the NRC (2001) Model}

The exponential model is functionally similar to the modified equation of the NRC (2001), except that the NRC (2001) equation is based on weekly mean values of DMI and contained BW, 4\% FCM, and a correction factor for week of lactation. The NRC (2001) equation provided a good basis for comparison, provided the exponential model was also fitted to weekly mean DMI and inferences could then be drawn from those results. For comparison between the NRC (2001) and exponential models, weekly mean DMI was predicted by both equations, and the accuracy of prediction and robustness were then compared.

Based on all model selection criteria used in this study, overall prediction of weekly DMI for individual cows by the exponential model was superior to the NRC (2001) equation (Table 7). The exponential model explained $85 \%$ of the variation in weekly mean DMI compared with $42 \%$ for the NRC (2001). Compared with the exponential model, a 2-fold higher RPE was associated with prediction using the NRC (2001) equation $(6$ and $14 \%$, respectively). The overall mean MSPE value for individual cows was 5 -fold higher for the NRC (2001) than for the exponential model (10.43 vs. $2.01 \mathrm{~kg}^{2} / \mathrm{d}^{2}$ ). For both Illinois and New Hampshire cows, the NRC
(2001) equation underpredicted weekly mean DMI at one stage or another of early lactation. For Illinois cows, the NRC (2001) equation underpredicted DMI from wk 3 to 10 , and the underprediction increased as lactation progressed (Figure 4a). Underprediction of weekly mean DMI of New Hampshire cows by the NRC (2001) equation (Figure 4b) was less severe than for Illinois cows and occurred mainly from wk 1 to 4 of lactation. For both groups of cows, the exponential model prediction of weekly mean DMI was very close to actual DMI (Figure 4, a and b).

The overall prediction accuracy of weekly mean DMI across week of lactation for Illinois cows was very high for the exponential model $\left(\mathrm{MSPE}=1.7 \mathrm{~kg}^{2} / \mathrm{d}^{2}, \mathrm{MPE}=\right.$ $1.3 \mathrm{~kg} / \mathrm{d}$, and RPE $=6 \%$ ) compared with the NRC (2001) equation $\left(\mathrm{MSPE}=11.9 \mathrm{~kg}^{2} / \mathrm{d}^{2}, \mathrm{MPE}=3.5 \mathrm{~kg} / \mathrm{d}\right.$, and $\mathrm{RPE}=17 \%$ ). When prediction of weekly mean DMI data was evaluated for each week and various periods during early lactation, the accuracy of the exponential model was consistent with the findings for daily DMI (Table 8). The least prediction accuracy for the exponential model was noted during wk 7 of lactation $(\mathrm{MSPE}=3.9$ $\mathrm{kg}^{2} / \mathrm{d}^{2}$ ), and the best was noted for wh 1 of lactation $\left(\mathrm{MSPE}=0.49 \mathrm{~kg}^{2} / \mathrm{d}^{2}\right)$. Conversely, the MSPE estimates from the NRC (2001) equation were much higher than those from the exponential model and ranged from 7.4 $\mathrm{kg}^{2} / \mathrm{d}^{2}$ for wk 2 of lactation to 20.4 for wk 10 of lactation. Throughout the first $10 \mathrm{wk}$ of lactation, the exponential model predicted weekly mean DMI with an RPE of $\leq 9 \%$ 
Table 7. Summary of the fit of the NRC (2001) and exponential ${ }^{1}$ (EXP) models of DMI

\begin{tabular}{lccccccr}
\hline Criterion $^{2}$ & Mean & SD & Minimum & Median & Maximum & CV & Higher $^{3}$ \\
\hline $\mathrm{R}^{2}{ }_{\text {NRC }}$ & 0.42 & 0.24 & 0.03 & 0.48 & 0.80 & 56.4 & 7 \\
$\mathrm{R}_{\text {EXP }}$ & 0.85 & 0.12 & 0.46 & 0.90 & 0.99 & 14.2 & 38 \\
MSPE $_{\text {NRC }}$ & 10.4 & 8.1 & 1.8 & 8.5 & 22.5 & 77.2 & 43 \\
MSPE $_{\text {EXP }}$ & 2.0 & 1.7 & 0.3 & 1.6 & 9.3 & 87.0 & 2 \\
MPE $_{\text {NRC }}$ & 3.0 & 1.1 & 1.4 & 2.9 & 6.3 & 36.1 & 43 \\
MPE $_{\text {EXP }}$ & 1.3 & 0.6 & 0.5 & 1.2 & 3.1 & 41.7 & 2 \\
$\mathrm{RPE}_{\mathrm{NRC}}$ & 13.8 & 4.9 & 6.1 & 13.8 & 25.8 & 35.6 & 43 \\
$\mathrm{RPE}_{\mathrm{EXP}}$ & 6.0 & 2.7 & 2.5 & 5.6 & 14.8 & 45.2 & 2 \\
$\mathrm{RSS}_{\mathrm{NRC}}$ & 103.9 & 80.8 & 18.2 & 85.4 & 399.9 & 77.8 & 42 \\
$\mathrm{RSS}_{\mathrm{EXP}}$ & 20.1 & 17.5 & 2.9 & 15.5 & 93.0 & 87.0 & 3 \\
\hline
\end{tabular}

${ }^{1} \mathrm{DMI}(\mathrm{t})=\mathrm{a}-\mathrm{b} \mathrm{e}^{-\mathrm{ct}}$, where $\mathrm{DMI}(\mathrm{t})=$ daily $\mathrm{DMI}$ for corresponding $\mathrm{DIM}, \mathrm{a}=$ asymptotic maximum DMI, $b=$ potential increase in DMI, $c=$ fractional rate of increase of DMI with DIM, and $t=$ DIM.

${ }^{2} \mathrm{MSPE}=$ Mean square prediction error $\left(\mathrm{kg}^{2} / \mathrm{d}^{2}\right), \mathrm{MPE}=$ square root of MSPE $(\mathrm{kg} / \mathrm{d}), \mathrm{RPE}=\mathrm{MPE}$ as a proportion of mean, and RSS = residual SS.

${ }^{3}$ Total number of cows with estimates greater than the mean value.
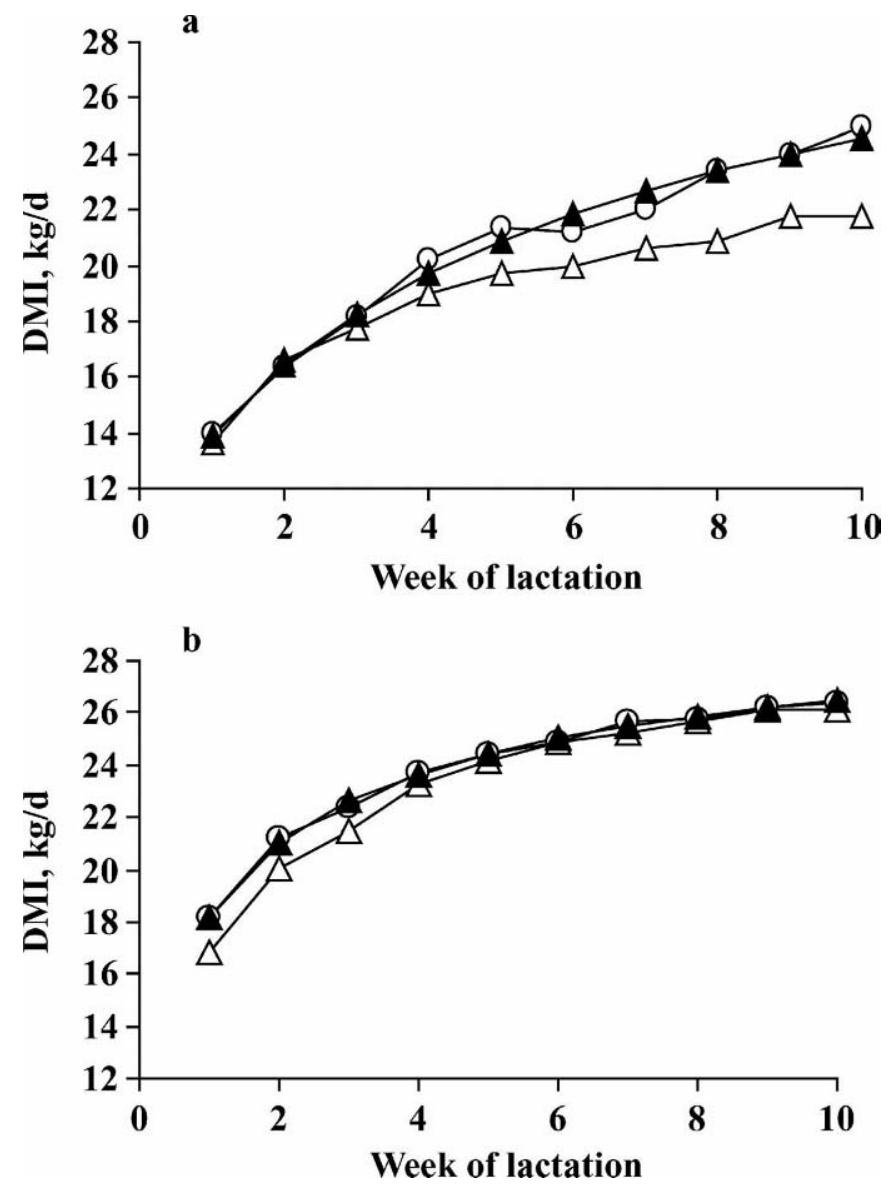

Figure 4. Weekly mean DMI $(\mathrm{kg} / \mathrm{d})$ observed $(\bigcirc)$, predicted with the exponential model $(\boldsymbol{\Delta})$ or predicted with $\operatorname{NRC}(2001)$ model $(\triangle)$ for a) Illinois (Erickson et al., 2000) or b) New Hampshire (Wasserstorm, 1996) cows. for Illinois cows, and the NRC (2001) RPE estimates were mostly $>15 \%$. Based on these estimates, the exponential model would be considered to have satisfactory accuracy; whereas, the NRC (2001) model would have acceptable accuracy ["satisfactory and acceptable" as defined by Fuentes-Pila et al. (1996)]. The same trend was observed for overall prediction accuracy of weekly mean DMI for New Hampshire cows (Table 8).

\section{Components of MSPE for the NRC (2001) and the Exponential Model of DMI}

Overall, a high proportion of MSPE was associated with its random variation component for both exponential and NRC (2001) models (Table 9). Values for random variation for the exponential model confirmed the high reduction in actual DMI variance values by taking weekly means of DMI. An overall 4-fold smaller random variation was associated with the exponential model compared with the NRC (2001) model. The difference in random variation between the NRC (2001) and the exponential models was because of a higher $\mathrm{R}^{2}$ for the exponential model compared with the NRC (2001) model ( 0.89 vs. 0.51 overall; 0.91 vs. 0.48 for Illinois cows and 0.82 vs. 0.40 for New Hampshire cows). The variance of actual DMI was similar for both models (20.4 overall; 19.4 for Illinois cows and 15.8 for New Hampshire cows). These values suggest that $\left(1-R^{2}\right)$ was the major cause of inaccuracy in prediction of daily DMI by the NRC (2001) model. In previous studies, coefficients of determination that were $<0.50$ were considered as an indication that a DMI prediction equation was not explaining a large proportion of actual variation in DMI (Yungblut et al., 1981; Fuentes-Pila et al., 1996).

The mean and line bias values were almost zero with all datasets for the exponential model (Table 9), sug- 
Table 8. Comparison of NRC (2001) and exponential ${ }^{1}$ (EXP) models for accuracy of predicting weekly DMI in Illinois (Erickson et al., 2000) and New Hampshire (Wasserstorm, 1996) cows

\begin{tabular}{|c|c|c|c|c|c|c|}
\hline \multirow{2}{*}{$\begin{array}{l}\text { Week of } \\
\text { lactation }\end{array}$} & \multicolumn{2}{|c|}{$\mathrm{MSPE}^{2}$} & \multicolumn{2}{|c|}{$\mathrm{MPE}^{3}$} & \multicolumn{2}{|c|}{$\mathrm{RPE}^{4}$} \\
\hline & NRC & EXP & NRC & EXP & NRC & EXP \\
\hline \multirow{2}{*}{\multicolumn{7}{|c|}{$\begin{array}{l}\text { Illinois } \\
\text { cows }\end{array}$}} \\
\hline & & & & & & \\
\hline All & 11.93 & 1.71 & 3.45 & 1.31 & 0.17 & 0.06 \\
\hline 1 & 10.76 & 0.49 & 3.28 & 0.70 & 0.23 & 0.05 \\
\hline 2 & 7.43 & 1.27 & 2.73 & 1.13 & 0.17 & 0.07 \\
\hline 3 & 7.80 & 1.15 & 2.79 & 1.07 & 0.15 & 0.06 \\
\hline 4 & 7.80 & 1.13 & 2.79 & 1.06 & 0.14 & 0.05 \\
\hline 5 & 9.84 & 1.72 & 3.14 & 1.31 & 0.15 & 0.06 \\
\hline 6 & 9.72 & 3.00 & 3.12 & 1.73 & 0.15 & 0.08 \\
\hline 7 & 12.19 & 3.94 & 3.49 & 1.98 & 0.16 & 0.09 \\
\hline 8 & 16.76 & 1.57 & 4.09 & 1.25 & 0.17 & 0.05 \\
\hline 9 & 16.67 & 1.45 & 4.08 & 1.20 & 0.17 & 0.05 \\
\hline 10 & 20.37 & 1.36 & 4.51 & 1.17 & 0.18 & 0.05 \\
\hline 1 to 5 & 8.73 & 1.15 & 2.95 & 1.07 & 0.16 & 0.06 \\
\hline 6 to 10 & 15.14 & 2.27 & 3.89 & 1.51 & 0.17 & 0.07 \\
\hline 2 to 4 & 7.68 & 1.18 & 2.77 & 1.09 & 0.15 & 0.06 \\
\hline 5 to 7 & 10.58 & 2.89 & 3.25 & 1.70 & 0.15 & 0.08 \\
\hline 8 to 10 & 17.93 & 1.46 & 4.23 & 1.21 & 0.18 & 0.05 \\
\hline \multicolumn{7}{|c|}{ New Hampshire cows } \\
\hline All & 11.79 & 2.81 & 3.43 & 1.68 & 0.14 & 0.07 \\
\hline 1 & 15.13 & 0.60 & 3.89 & 0.77 & 0.21 & 0.04 \\
\hline 2 & 12.53 & 1.02 & 3.54 & 1.01 & 0.17 & 0.05 \\
\hline 3 & 17.19 & 4.12 & 4.15 & 2.03 & 0.19 & 0.09 \\
\hline 4 & 9.53 & 3.61 & 3.09 & 1.90 & 0.13 & 0.08 \\
\hline 5 & 10.91 & 2.23 & 3.30 & 1.49 & 0.13 & 0.06 \\
\hline 6 & 12.61 & 3.02 & 3.55 & 1.74 & 0.14 & 0.07 \\
\hline 7 & 12.18 & 4.16 & 3.49 & 2.04 & 0.14 & 0.08 \\
\hline 8 & 8.19 & 3.39 & 2.86 & 1.84 & 0.11 & 0.07 \\
\hline 9 & 9.31 & 3.11 & 3.05 & 1.76 & 0.12 & 0.07 \\
\hline 10 & 10.63 & 2.86 & 3.26 & 1.69 & 0.12 & 0.06 \\
\hline 1 to 5 & 12.81 & 2.32 & 3.58 & 1.52 & 0.16 & 0.07 \\
\hline 6 to 10 & 10.77 & 3.30 & 3.28 & 1.82 & 0.13 & 0.07 \\
\hline 2 to 4 & 13.09 & 2.92 & 3.62 & 1.71 & 0.16 & 0.08 \\
\hline 5 to 7 & 11.88 & 3.13 & 3.45 & 1.77 & 0.14 & 0.07 \\
\hline 8 to 10 & 9.37 & 3.12 & 3.06 & 1.77 & 0.12 & 0.07 \\
\hline
\end{tabular}

${ }^{1} \mathrm{DMI}(\mathrm{t})=\mathrm{a}-\mathrm{b} \mathrm{e}^{-\mathrm{ct}}$, where $\mathrm{DMI}(\mathrm{t})=$ daily DMI for corresponding DIM, a = asymptotic maximum DMI, $\mathrm{b}=$ potential increase in DMI, $\mathrm{c}=$ fractional rate of increase of DMI with DIM, and $\mathrm{t}=$ DIM.

${ }^{2}$ Mean square prediction error $\left(\mathrm{kg}^{2} / \mathrm{d}^{2}\right)$.

${ }^{3}$ Mean prediction error (kg/d).

${ }^{4}$ Relative proportional error; prediction error proportion of the mean.

gesting it had high accuracy in the prediction of DMI and was robust. The NRC (2001) model mean bias and line bias values showed that the model consistently underpredicted DMI with all datasets. Underprediction with the NRC (2001) model for Illinois cows was higher compared with the overall and New Hampshire cows $(1.4 \mathrm{~kg} / \mathrm{d}$ vs. 1.0 and $0.4 \mathrm{~kg} / \mathrm{d}$, respectively). For ration formulation, underprediction may not be as serious as overprediction (Yungblut et al., 1981); however, DMI underprediction could be more costly when feed costs are predicted in decision support models (Fuentes-Pila et al., 1996). Underprediction of DMI will cause underprediction of feed costs, and feed costs represent approximately one-half of the total cost of production (Kennedy et al., 1993; AFRC, 1998); therefore, profitability would be overestimated.
The line bias values for the NRC (2001) were under unity overall (0.91) and for Illinois cows (0.01) and were comparatively higher for New Hampshire cows (2.18). The high line bias values indicate underlying inadequacies in the structure of the model (Neal et al., 1984). Large line bias values for New Hampshire cows and low values for Illinois cows with the NRC (2001) model suggest that the coefficients used in the NRC (2001) model may reflect conditions similar to those encountered by the Illinois cows. Although the mean bias component of the MSPE could be improved partially by addition of a constant term in the equation, no easy remedy exists for large line bias or random variation (Neal et al., 1984).

The NRC (2001) model was thought to be an accurate and robust predictor of DMI of Holstein cows; however, 
Table 9. Prediction accuracy and mean square prediction error components of the NRC (2001) and exponen$\operatorname{tial}^{1}$ (EXP) models for weekly mean DMI of Illinois (Erickson et al., 2000) and New Hampshire (Wasserstorm, 1996) cows

\begin{tabular}{|c|c|c|c|c|}
\hline $\begin{array}{l}\text { Week of } \\
\text { lactation }\end{array}$ & $\begin{array}{l}\text { Mean } \\
\text { bias }^{2}\end{array}$ & $\begin{array}{l}\text { Line } \\
\text { bias }^{3}\end{array}$ & $\begin{array}{l}\text { Random } \\
\text { variation }\end{array}$ & $\begin{array}{l}\text { Mean } \\
\text { proportional } \\
\text { bias }^{5}\end{array}$ \\
\hline \multicolumn{5}{|c|}{$\begin{array}{l}\text { All cows } \\
\text { wk } 1 \text { to } 10\end{array}$} \\
\hline NRC & 0.950 & 0.906 & 9.996 & -0.035 \\
\hline EXP & 0.000 & 0.000 & 2.244 & 0.000 \\
\hline \multicolumn{5}{|l|}{ wk 7} \\
\hline NRC & 0.890 & 1.881 & 9.660 & -0.029 \\
\hline EXP & -0.260 & 0.037 & 4.060 & 0.010 \\
\hline \multicolumn{5}{|c|}{$\begin{array}{l}\text { Illinois cows } \\
\text { wk } 1 \text { to } 10\end{array}$} \\
\hline NRC & 1.410 & 0.006 & 10.088 & -0.071 \\
\hline EXP & 0.000 & 0.000 & 1.746 & 0.000 \\
\hline \multicolumn{5}{|l|}{ wk 7} \\
\hline NRC & 1.390 & 0.306 & 10.248 & -0.064 \\
\hline EXP & 0.028 & 0.036 & 3.538 & 0.028 \\
\hline \multicolumn{5}{|c|}{ New Hampshire cows } \\
\hline NRC & 0.450 & 2.182 & 9.480 & -0.010 \\
\hline EXP & 0.000 & 0.000 & 2.844 & 0.000 \\
\hline \multicolumn{5}{|l|}{ wk 7} \\
\hline NRC & 0.380 & 4.168 & 8.188 & -0.006 \\
\hline EXP & -0.005 & 0.056 & 4.232 & -0.005 \\
\hline
\end{tabular}

${ }^{1} \mathrm{DMI}(\mathrm{t})=\mathrm{a}-\mathrm{b} \mathrm{e}^{-\mathrm{ct}}$, where $\mathrm{DMI}(\mathrm{t})=$ daily $\mathrm{DMI}$ for corresponding $\mathrm{DIM}$, a = asymptotic maximum DMI, $\mathrm{b}=$ potential increase in DMI, $\mathrm{c}=$ fractional rate of increase of DMI with DIM, and $\mathrm{t}=$ DIM.

${ }^{2}$ Mean bias = observed $(\mathrm{O})$ minus predicted $(\mathrm{P})$ means DMI $(\mathrm{kg} / \mathrm{d})$.

${ }^{3}$ Line bias $=(1-b)^{2} \times S^{2}$, where $\mathrm{b}$ is the slope of the regression of $\mathrm{O}$ on $\mathrm{P}$ and $\mathrm{S}_{\mathrm{p}}^{2}=$ variance of the predicted DMI $\left(\mathrm{kg} / \mathrm{d}^{2}\right)$.

${ }^{4}$ Random variation $=\left(1-R^{2}\right) \times S^{2}$, where $R^{2}$ is the coefficient of determination for the regression of $O$ on $\mathrm{P}$ and $\mathrm{S}^{2}{ }_{\mathrm{O}}=$ variance of the observed DMI $\left(\mathrm{kg} / \mathrm{d}^{2}\right)$.

${ }^{5}$ Mean proportion bias = deviation from unity, expressed as a percentage of one of the slope of a regression analysis of $\mathrm{P}$ on $\mathrm{O}$ with the intercept forced to be zero.

this analysis suggests otherwise. Low coefficients of determination $(<0.50)$ and lack of consistency in the accuracy of prediction of DMI for different sets of data do not suggest that the NRC (2001) model accurately or robustly predicts DMI (Yungblut et al., 1981; Fuentes-Pila et al., 1996). High accuracy for some datasets (Illinois) and poor accuracy for others (New Hampshire) suggests that use of the NRC (2001) model is risky. Conversely, the exponential model accurately and consistently predicted DMI for all cows. Although exponential model was developed using Holstein data, it can also be used with different parameters for predicting the DMI of Jersey cows (Murphy and Shah, 1999).

\section{CONCLUSIONS}

The consistently accurate and robust prediction of DMI by the exponential model for all datasets suggested that it could safely be used for predicting DMI in many circumstances. Based on all model selection and comparison criteria used in this study, the prediction accuracy and robustness of the exponential model was superior to the NRC (2001) model for all datasets. Although all parameters of the exponential model have simple biological interpretations, further evaluation of the relationships between them and other variables, e.g. prepartum DMI and BW, may provide insight into their potential estimation. These parameters could be used in diet evaluation and genetic selection.

\section{ACKNOWLEDGMENT}

The authors thank N. A. Janovick Guretzky for her helpful comments and suggestions.

\section{REFERENCES}

AFRC. 1998. Response in the Yield of Milk Constituents to the Intake of Nutrients by Dairy Cows. CAB Int., Wallingford, UK.

Bibby, J., and H. Toutenburg. 1977. Prediction and Improved Estimation in Linear Models. John Wiley \& Sons, London, UK.

Chase, L. E. 1993. Developing nutrition programs for high producing dairy herds. J. Dairy Sci. 76:3287-3293.

Chilliard, Y., M. Cissé, R. Lefaivre, and B. Rémond. 1991. Body composition of dairy cows according to lactation stage, somatotropin treatment, and concentrate supplementation. J. Dairy Sci. 74:3103-3116.

Cooper, R. J., T. J. Klopfenstein, R. A. Stock, C. T. Milton, D. W. Herold, and J. C. Parrott. 1999. Effects of imposed feed intake 
variation on acidosis and performance of finishing steers. J. Anim. Sci. 77:1093-1099.

Coulon, J.-B. 1981. Intake capacity of milk cows at the beginning of lactation: Development and connections with some behavioral, digestive, metabolic and health parameters. Ph.D. Diss., École Natl. Supérieure Agron. de Montpellier, France.

Dann, H. M., G. A. Varga, and D. E. Putnam. 1999. Improving energy supply to late gestation and early postpartum dairy cows. J. Dairy Sci. 82:1765-1778

Draper, N. R., and H. Smith. 1996. Applied Regression Analysis. 2nd ed. John Wiley \& Sons Co., New York, NY.

Erickson, P. S., M. R. Murphy, J. M. Campbell, and S. W. Nombekela. 2000. Lasalocid supplementation of dairy cows diets in early lactation. Prof. Anim. Scient. 16:196-201.

Forbes, J. M., and F. D. Provenza. 2000. Integration of learning and metabolic signals into a theory of dietary choice and food intake. Pages 3-39 in Ruminant Physiology, Digestion, Metabolism, Growth and Reproduction. P. B. Cronjé, ed. CAB Int., Wallingford, UK.

Fuentes-Pila, J., M. A. DeLorenzo, D. K. Beede, C. R. Staples, and J. B. Holter. 1996. Evaluation of equations based on animal factors to predict intake of lactating Holstein cows. J. Dairy Sci. 79:1562-1571.

Fuentes-Pila, J., M. Ibañez, J. M. De Miguel, and D. K. Beede. 2003. Predicting average feed intake of lactating Holstein cows fed totally mixed rations. J. Dairy Sci. 86:309-323.

Hayirli, A., R. R. Grummer, E. V. Nordheim, and P. M. Crump. 2003. Models for predicting dry matter intake of Holsteins during the prefresh transition period. J. Dairy Sci. 86:1771-1779.

Holter, J. B., J. W. West, and M. L. McGilliard. 1996. Predicting ad libitum dry matter intake and yield of Holstein cows. J. Dairy Sci. 80:2188-2199.

Ingvartsen, K. L. 1994. Models of voluntary food intake in cattle. Livest. Prod. Sci. 39:19-38.

Ingvartsen, K. L., and J. B. Andersen. 2000. Integration of metabolism and intake regulation: A review focusing on periparturient animals. J. Dairy Sci. 83:1573-1597.

Ingvartsen, K. L., H. R. Andersen, and J. Foldager. 1992. Random variation in voluntary dry matter intake and the effect of day length on feed intake capacity in growing cattle. Acta Agric. Scand. Sect. A Anim. Sci. 42:121-126.

Kabuga, J. D. 1992. Accuracy of some published feed intake prediction equations for dairy cows in Ghana. Trop. Agric. 69:58-62.

Kennedy, B. W., J. H. J. van der Werf, and T. H. E. Meuwissen. 1993. Genetic and statistical properties of residual feed intake. J. Anim. Sci. 71:3239-3250.

Kertz, A. F., L. F. Reutzel, and G. M. Thomson. 1991. Dry matter intake from parturition to midlactation. J. Dairy Sci. 74:22902295.

Loague, K., and R. E. Green. 1991. Statistical and graphical methods for evaluating solute transport models: Overview and application. J. Contam. Hydrol. 7:51-73.

Mason, S., and J. Kennelly. 2001. How much do cows eat? Dairy Res. Highlights. Univ. of Alberta. Available: http://www.westerndairy-
science.com/html/U\%20of\%20A\%20articles/html/Intake2.html. Accessed Nov. 22, 2004

Mayer, D. G., and D. G. Butler. 1993. Statistical validation. Ecol. Model. 68:21-32.

McGuffey, R., J. Symanowski, J. Kube, J. Shirley, R. Wallace, and J. Clark. 1997. Variation in feed intake as a predictor for the subsequent occurrence of health conditions in the postpartum transition cow. J. Dairy Sci. 80(Suppl. 1):251. (Abstr.)

Mertens, D. R. 1995. Methods in modeling feeding behaviour and intakes in herbivores. Pages 1-17 in IVth Int. Symp. Nutr. Herbivores. Inst. Natl. Agron. Paris-Grignon and INRA, Paris.

Murphy, M. R., and M. A. Shah. 1999. Algunos factores fisiologicos de comportamiento y de medio ambiente que afectan el consumo de alimento en vacas lecheras. Pages 55-67 in Seminaro Sobre Nutricion y Alimentacion de Ganado Bovino Productor de Leche, Assoc. Mexico Espec. Nutr. Anim., Aguascalientes, Ags., Mexico.

National Research Council. 2001. Nutrient Requirements of Dairy Cattle. 7th rev. ed. Natl. Acad. Sci., Washington, DC.

Neal, H. D. C., C. Thomas, and J. M. Cobby. 1984. Comparison of equations for predicting voluntary intake by dairy cows. J. Agric. Sci. (Camb.) 103:1-10.

Picard, R. R., and R. D. Cook. 1984. Cross-validation of regression models. J. Am. Stat. Assoc. 79:575-583.

Rayburn, E. B., and D. G. Fox. 1993. Variation in neutral detergent fiber intake of Holstein cows. J. Dairy Sci. 76:544-554.

Rémond, B. 1988. Evolution du poids du contenu du réticulo-rumen chez les vaches laitiéres au cours des deus deux premiers mois de la lactation. Reprod. Nutr. Dévelop. 28:109-110.

Rook, A. J., M. Gill, R. D. Willink, and S. J. Lister. 1991. Prediction of voluntary intake of grass silages by lactating cows offered concentrates at a flat rate. Anim. Prod. 52:407-420.

Roseler, D. K., D. G. Fox, L. E. Chase, and W. C. Stone. 1993. Feed intake prediction and diagnosis in dairy cows. Pages 216-226 in Proc. Cornell Nutr. Conf. Feed Manuf., Ithaca, NY. Cornell Univ., Ithaca, NY.

Roseler, D. K., D. G. Fox, A. N. Pell, and L. E. Chase. 1997a. Evaluation of alternative equations for prediction of intake for Holstein dairy cows. J. Dairy Sci. 80:864-877.

Roseler, D. K., D. G. Fox, L. E. Chase, A. N. Pell, and W. C. Stone. 1997b. Development and evaluation of equations for prediction of feed intake for lactating Holstein dairy cows. J. Dairy Sci. 80:878-893.

SAS/STAT User's Guide. Version 8.1. 1997. SAS Inst., Inc., Cary, NC. Schaeffer, D. L. 1980. A model evaluation methodology applicable to environmental assessment models. Ecol. Model. 8:275-295.

Sherrod, P. H. 2000. Nonlinear Regression Analysis Program, NLREG Version 5.0 Phillip H. Sherrod, Nashville, TN.

Vadiveloo, J., and W. Holmes. 1979. The prediction of the voluntary feed intake of dairy cows. J. Agric. Sci. (Camb.) 93:553-562.

Wasserstorm, V. 1996. Optimizing lysine and methionine nutrition during the periparturient and postparturient periods. Ph.D. Diss., Univ. New Hampshire, Durham.

Yungblut, D. H., J. B. Stone, G. K. Macleod, and G. F. Wilson. 1981. The testing of several feed intake prediction equations using farm data. Can. J. Anim. Sci. 61:159-164. 